\title{
Factors contributing to the increased threat to life following spinal cord injury
}

\author{
J E Kiwerski MD ScD
}

Rehabilitation Clinic of the Medical Academy in Warsaw, Konstancin, Poland.

\begin{abstract}
An analysis of the mortality rate of 3486 spinal injured patients treated in the early posttraumatic period in the years 1965-1989 in Konstancin, Poland is presented. The data show that the life of the spinal cord injured is threatened by several factors, the most important of which appear to be: the level and degree of the spinal cord lesion; certain causes of injury predisposing to severe nervous system injury; advanced age; and to some extent, concomitant injuries and methods of treatment. The significance of age is demonstrated by a nearly tenfold increase in mortality in the oldest age group of patients with complete spinal cord lesions as compared to the youngest age group of up to 20 years with the same degree of spinal cord damage.
\end{abstract}

Keywords: traumatic spinal cord injury; mortality.

\section{Introduction}

The problem of mortality following spinal cord injury is rarely tackled in medical literature. ${ }^{1.2 .3}$ Still less frequently discussed are the causes of death and the factors contributing to this from such causes. ${ }^{4.5 .6}$ The usually reported data concern the total mortality rate in the spinal cord injured, regardless of the degree and the level of the spinal cord injury and of the age of the patient. Therefore the mortality rates reported by some authors sometimes show surprising disparities, but do not reflect the value of the actual method of treatment that was provided. The mortality rate may be as low as a few percent in patients with partial injuries involving the lower segments of the spinal cord; and may be 10 times higher in patients with high location complete spinal cord lesion, especially in older patients. ${ }^{7.8}$ Therefore the only comparable groups must consist of patients with similar degrees of spinal cord lesion, and at the same level. Based on a large number of treated patients the author attempts to evaluate the various factors that appear to increase the possibility of death in patients with a spinal cord injury.

\section{Material and methods}

To illustrate this problem better an analysis of the mortality of 3486 patients with a spinal injury admitted in the early posttraumatic period (from a few hours to 2 weeks following injury) in the years 1965-1989, is provided. Table I details the clinical material, including the level and degree of the spinal injury, and the number of deaths in the particular groups. It confirms two earlier observations. (1) The mortality is to a large extent dependent upon the level of the spinal cord lesion: in those with cervical spinal lesions it exceeded $15 \%$, in thoracic lesions it was $7.5 \%$ and in those with lumbar lesions $2.4 \%$. (2) The mortality rate is largely dependent on the degree of spinal cord injury and amounted to nearly $18 \%$ in those with complete injuries, was much lower in those with massive injuries and definitely lowest in those with injuries with the least degree of neurological involvement $(0.7 \%)$.

The mortality rate was highest in patients admitted with evidence of a complete spinal cord injury, being $29.7 \%, 9.3 \%$ and $4.7 \%$ in the cervical, thoracic and lumbar regions, respectively. The remaining tables include 
Table I Mortality and the level of the spinal injury

\begin{tabular}{|c|c|c|c|c|c|c|c|c|}
\hline \multirow{3}{*}{$\begin{array}{l}\text { Nervous system } \\
\text { injury }\end{array}$} & \multicolumn{6}{|c|}{ Level of spinal injury } & \multirow[t]{3}{*}{ Total } & \multirow{3}{*}{$\begin{array}{c}\text { Mortality } \\
\%\end{array}$} \\
\hline & \multicolumn{2}{|c|}{ Cervical } & \multicolumn{2}{|c|}{ Thoracic } & \multicolumn{2}{|c|}{ Lumbar } & & \\
\hline & Alive & Dead & Alive & Dead & Alive & Dead & & \\
\hline \multicolumn{9}{|l|}{ Complete } \\
\hline Frankel grade A & 487 & 206 & 391 & 40 & 326 & 16 & 1466 & $17.9 \%$ \\
\hline \multicolumn{9}{|l|}{ Incomplete } \\
\hline Frankel grade B & 195 & 12 & 28 & 1 & 62 & 1 & 299 & $4.7 \%$ \\
\hline Frankel grade C & 312 & 22 & 45 & 3 & 134 & 6 & 522 & $5.9 \%$ \\
\hline Frankel grade D & 368 & 3 & 23 & 1 & 130 & - & 535 & $0.7 \%$ \\
\hline \multicolumn{9}{|c|}{ Without neurological involvement } \\
\hline Frankel grade E & 243 & - & 100 & - & 321 & - & 664 & 0 \\
\hline Total & 1605 & $\begin{array}{c}243 \\
(15.1 \%)\end{array}$ & 597 & $\begin{array}{c}45 \\
(7.5 \%)\end{array}$ & 973 & $\begin{array}{c}23 \\
(2.4 \%)\end{array}$ & 3468 & $8.9 \%$ \\
\hline
\end{tabular}

smaller numbers of patients because only those with symptoms of spinal cord injury on admission were included. Table II shows the number of patients who were treated because of injury to particular segments of the spine, and the number of deaths in those with complete and those with partial spinal cord lesions. The number of patients tends to increase in the subsequent periods. The mortality rate in the analysed group of patients was $11 \%$, with a tendency to diminish in the subsequent periods, from $12.6 \%$ to $8.8 \%$ in the last period.

The most frequent causes of the spinal injuries (Table III) were: falls from a horsecart $(17 \%$ of all cases), diving $(12 \%)$. automobile accidents $(12 \%)$, motorcycle accidents $(8 \%)$, and falls from a ladder or stairs $(7 \%)$. The mortality rate was highest in: falls from scaffolding $(21 \%)$, from a horse-cart $(20 \%)$, from a roof $(19 \%)$, injuries sustained by pedestrians struck by motor vehicles $(16 \%)$, and falls from a great height $(10 \%)$.

The mortality in subsequent age groups in relation to the level and to the degree of spinal cord injury is set out in Table IV. In the first two age groups the mortality is relatively low. The mortality rate increases markedly in those over the age of 40 years, and is nearly tenfold higher in individuals over 60 years of age than in the youngest

Table II Mortality 1965-1989

\begin{tabular}{lcccc}
\hline Injury location & \multicolumn{4}{c}{ Deaths } \\
\cline { 2 - 5 } & $1965-1973$ & $1974-1981$ & $1982-1989$ & Total \\
\hline Cervical & 396 & 445 & 521 & 1362 \\
Complete & 73 & 79 & 54 & 206 \\
Incomplete & 10 & 16 & 11 & 37 \\
Thoracic & 114 & 179 & 209 & 497 \\
Complete & 13 & 10 & 17 & 40 \\
Incomplete & 1 & 3 & 1 & 5 \\
Lumbar & 217 & 238 & 197 & 652 \\
Complete & 7 & 5 & 4 & 16 \\
Incomplete & 1 & 3 & 3 & 7 \\
Total & 832 & 973 & 1017 & 2822 \\
Mortality $(\%)$ & 12.6 & 11.9 & 8.8 & 11 \\
\hline
\end{tabular}


Table III Mortality and the level of the spinal injury

\begin{tabular}{|c|c|c|c|c|c|c|c|c|}
\hline \multirow[t]{3}{*}{ Cause of injury } & \multicolumn{6}{|c|}{ Injured spinal cord segment } & \multirow[t]{3}{*}{ Total } & \multirow{3}{*}{$\underset{\%}{\text { Deaths }}$} \\
\hline & \multicolumn{2}{|c|}{ Cervical } & \multicolumn{2}{|c|}{ Thoracic } & \multicolumn{2}{|c|}{ Lumbar } & & \\
\hline & Alive & Dead & Alive & Dead & Alive & Dead & & \\
\hline \multicolumn{9}{|l|}{ Falls } \\
\hline Horse-cart & 317 & 82 & 40 & 11 & 28 & 3 & 481 & 20 \\
\hline Diving & 298 & 31 & 1 & - & - & - & 330 & 9 \\
\hline Roof & 36 & 20 & 46 & 8 & 43 & 2 & 155 & 19 \\
\hline Scaffolding & 23 & 13 & 22 & 5 & 36 & 3 & 102 & 21 \\
\hline Ladder, stairs & 114 & 12 & 24 & 3 & 50 & 3 & 206 & 9 \\
\hline Tree & 48 & 7 & 32 & 5 & 70 & - & 162 & 7 \\
\hline Suicidal jumps & 8 & 2 & 23 & 1 & 59 & 1 & 94 & 4 \\
\hline From small height & 92 & 5 & 18 & - & 34 & 1 & 150 & 4 \\
\hline From great height & 32 & 8 & 28 & 2 & 46 & 2 & 118 & 10 \\
\hline \multicolumn{9}{|l|}{ Road accidents } \\
\hline Automobile & 162 & 26 & 73 & 1 & 66 & - & 328 & 8 \\
\hline Motorcycle & 51 & 9 & 98 & 5 & 41 & 1 & 205 & 7 \\
\hline Bicycle & 29 & 2 & 6 & - & 4 & - & 41 & 5 \\
\hline Pedestrians & 39 & 14 & 24 & 1 & 39 & 5 & 122 & 16 \\
\hline Other & 25 & 2 & 7 & - & 20 & 1 & 55 & 6 \\
\hline $\begin{array}{l}\text { Compression by a heavy } \\
\text { object }\end{array}$ & 41 & 5 & 27 & - & 85 & 1 & 159 & 4 \\
\hline Wounds & 2 & - & 15 & 1 & 4 & - & 22 & 5 \\
\hline Other causes & 45 & 5 & 13 & 2 & 27 & - & 92 & 8 \\
\hline Total & 1362 & 243 & 497 & 45 & 652 & 23 & 2822 & 11 \\
\hline
\end{tabular}

Table IV Age and mortality

\begin{tabular}{|c|c|c|c|c|c|c|}
\hline \multirow[t]{2}{*}{ Segment } & \multirow{2}{*}{$\begin{array}{l}\text { Degree of } \\
\text { injury }\end{array}$} & \multicolumn{4}{|c|}{ Age } & \multirow[t]{2}{*}{ Total } \\
\hline & & $0-20$ & $21-40$ & $41-60$ & Over 60 & \\
\hline \multirow{4}{*}{ Cervical } & Complete & 103 & 222 & 117 & 45 & 487 \\
\hline & Deaths & 11 & 44 & 73 & 78 & 206 \\
\hline & Incomplete & 106 & 269 & 294 & 209 & 875 \\
\hline & Deaths & 2 & 2 & 12 & 21 & 37 \\
\hline \multirow{4}{*}{ Thoracic } & Complete & 68 & 180 & 108 & 35 & 395 \\
\hline & Deaths & - & 8 & 12 & 20 & 40 \\
\hline & Incomplete & 22 & 46 & 25 & 13 & 106 \\
\hline & Deaths & - & 2 & 2 & 1 & 5 \\
\hline \multirow{4}{*}{ Lumbar } & Complete & 46 & 175 & 82 & 23 & 326 \\
\hline & Deaths & 1 & 4 & 2 & 9 & 16 \\
\hline & Incomplete & 46 & 163 & 94 & 23 & 326 \\
\hline & Deaths & 1 & - & 4 & 2 & 7 \\
\hline \multirow{4}{*}{ Total } & Complete & 229 & 633 & 394 & 210 & 1466 \\
\hline & Deaths (\%) & 5 & 9 & 22 & 60 & \\
\hline & Incomplete & 177 & 482 & 428 & 269 & 1356 \\
\hline & Deaths $(\%)$ & 2 & 1 & 4 & 9 & \\
\hline
\end{tabular}


group. Cervical spinal cord injuries are most frequent and have a higher mortality rate, in particular if the lesion is complete. Even in the youngest group the mortality amounts to nearly $10 \%$ and gradually increases with age to over $60 \%$ in those aged over 60 years who had been admitted with clinical evidence of a complete cervical lesion.

The leading causes of death, diagnosed partly on the basis of the anatomopathological findings and partly on the clinical data are shown in Table $\mathrm{V}$, together with the level and degree of nervous system injury. The leading cause of death was pneumonia $(52 \%)$. Pulmonary complications accounted for $74 \%$ of total deaths. These complications were understandably most frequent in patients with complete injuries to the cervical spinal cord. In that group alone there were some $13 \%$ of deaths caused by primary respiratory insufficiency, usually due to the high location of the complete spinal cord injury with associated diaphragm paralysis and sometimes also with brainstem disturbances and dysfunction of vital centers. ${ }^{9}$ Many patients in this group were brought to hospital with respiratory insufficiency, whilst others developed this within a few hours of the injury.

Next in relevance, although definitely less frequent $(8 \%)$, was death from abdominal complications (bleeding from the alimentary canal, rupture of gastric ulcers, etc). A slightly less frequent cause of death was severe, irreversible brain injury $(6 \%)$, usually accompanied by injury to the cervical spinal cord. Pneumonia was also the most commonly observed complication in those with complete thoracic and lumbar lesions $(35-31 \%)$.

The final table (VI) shows the survival time with regard to the most frequent causes of injury. The average survival time in the analysed group was 26.3 days, but varied greatly. In the first week after injury the mortality rate amounted to $74 \%$ in patients with primary respiratory insufficiency, and was also quite high in patients with rapidly developing bilateral pneumonia $(27 \%)$. In the second and third week after injury death was usually due to pneumonia (over $60 \%$ of deaths). Pulmonary embolism and abdominal complications were also likely to result in a fatal outcome in that period of time. In the late posttraumatic period mortality was low and was due mainly to late urinary complications, decubiti and subsequent septic conditions.

\section{Discussion}

Analysis of the clinical material shows that the life of the spinal cord injured individuals is threatened to various degrees by a number of factors of which the most relevant appear to be: the level and degree of the spinal cord injury; certain causes of the injury with the sequela of serious neurological involvement; older age of the patients and consequent cardiorespiratory problems; and the method of treatment, taking into account advanced medical techniques and the effectiveness of intensive care. ${ }^{10}$ The data in Tables I and II show irrefutably that the threat to life is greatest in patients with evidence of a complete cervical spinal cord injury. This refers not only to the relatively small number of patients who had been successfully transported to hospital despite the complete high location of the spinal cord lesion with diaphragm paralysis, but also to patients with complete spinal cord lesions from involvement of the lower cervical and sometimes of the higher thoracic spinal cord segments. Disturbed balance of the autonomic nervous system with preponderance of the parasympathetic system ${ }^{11-13}$ contributes to the increased retention of secretions in the respiratory tract. Simultaneous bronchospasm and inability to cough effectively, and to expectorate, caused by the paralysis of the chest muscles and often also by diaphragmatic paresis, render the removal of excessive secretions from the respiratory tract difficult. This leads to the rapid development of atelectasis, to reduction of the active respiratory space within the lungs, respiratory insufficiency and increasing anoxia. The retained secretions favour the development of bronchitis and bronchopneumonia. Understandably this is a great threat to life, in particular for patients advanced in years with a previously somewhat poor cardiorespiratory system. The cause of the injury also influences 
Table V Cause of death

Level and degree of spinal cord lesion

\begin{tabular}{|c|c|c|c|c|c|c|c|c|}
\hline \multirow[b]{2}{*}{ Cause of death } & \multicolumn{2}{|c|}{ Cervical } & \multicolumn{2}{|c|}{ Thoracic } & \multicolumn{2}{|c|}{ Lumbar } & \multicolumn{2}{|c|}{ Total } \\
\hline & Complete & Incomplete & Complete & Incomplete & Complete & Incomplete & Complete & Incomplete \\
\hline $\begin{array}{l}\text { Primary respiratory } \\
\text { insufficiency }\end{array}$ & 26 & 1 & - & - & - & - & 26 & 1 \\
\hline Pneumonia & 122 & 17 & 14 & 1 & 5 & 2 & 141 & 20) \\
\hline Pulmonary embolism & 9 & 5 & 4 & 1 & 3 & 2 & 16 & 8 \\
\hline Other pulmonary & 9 & 3 & 2 & - & 2 & - & 13 & 3 \\
\hline Myocardial infarction & 1 & - & 2 & - & - & - & 3 & - \\
\hline Brain injury & 13 & 2 & 4 & 1 & 1 & - & 18 & 3 \\
\hline Abdominal complications & 17 & 3 & 2 & 1 & 1 & 1 & 20 & 5 \\
\hline Renal insufficiency & 7 & 4 & 8 & - & 3 & 1 & 18 & 5 \\
\hline Decubiti sepsis & - & - & 1 & - & 1 & 1 & 2 & 1 \\
\hline Neoplasm & 1 & 1 & 2 & 1 & - & - & 3 & 2 \\
\hline Other causes & 1 & 1 & 1 & - & - & - & 2 & 1 \\
\hline Total & 206 & 37 & 40 & 5 & 16 & 7 & 262 & 49 \\
\hline
\end{tabular}


Table VI Time from injury to death

\begin{tabular}{|c|c|c|c|c|c|c|c|}
\hline \multirow[t]{2}{*}{ Cause of death } & \multicolumn{6}{|c|}{ Survival time } & \multirow[t]{2}{*}{ Total } \\
\hline & 1 weck & $2-3$ weeks & $4-6$ weeks & $7-12$ weeks & $4-6$ months & Over 6 months & \\
\hline $\begin{array}{l}\text { Primary respiratory } \\
\text { insufficiency }\end{array}$ & 20) & 7 & - & - & - & - & 27 \\
\hline Pneumonia & 44 & 97 & 14 & 7 & 1 & - & 161 \\
\hline Pulmonary embolism & - & 9 & 12 & 3 & - & - & 24 \\
\hline Other pulmonary & 3 & 5 & 7 & 1 & - & - & 16 \\
\hline Myocardial infarction & - & 1 & 2 & - & - & - & 3 \\
\hline Brain injury & 9 & 7 & 4 & 1 & - & - & 21 \\
\hline Abdominal complications & 5 & 15 & 4 & - & 1 & - & 25 \\
\hline Renal insufficiency & - & 3 & 8 & 3 & 4 & 5 & 23 \\
\hline Decubiti sepsis & - & - & - & - & 2 & 1 & 3 \\
\hline Neoplasm & - & 1 & 3 & 1 & - & - & 5 \\
\hline Other causes & 1 & 2 & - & - & - & - & 3 \\
\hline Total & 82 & 147 & 54 & 14 & 8 & 6 & 311 \\
\hline
\end{tabular}


prognosis. A fall from a height may result in relatively slight damage to vital organs and tissues, including the spinal cord, but such an occurrence is rather exceptional. Falls from great heights (scaffolding, roofs etc) usually cause a very high mortality rate. In motor vehicle accidents the most serious sequelae are incurred by pedestrians struck by motor vehicles. Falls from horse-carts also often result in a very high mortality, largely age related, with patients in their sixth or seventh decade.

The fact that the mortality rate is highest in patients with cervical lesions points to the important role of pulmonary complications as a cause of death. ${ }^{14-16}$ Such complications are less frequent but can also be life threatening in those with lower spinal cord lesions. Other factors which contribute to the increased life threatening effect in the early posttraumatic period and should be mentioned here are concomitant severe brain injury ${ }^{17-19}$ and abdominal complications, ${ }^{20.21}$ in particular bleeding from the alimentary tract. ${ }^{22}$ In the later posttraumatic period the greatest risk to life results from urinary complications leading to urosepsis, uraemia and renal insufficiency. Knowledge of the actual threats to life in SCI patients makes it possible to incorporate adequate preventative measures into the treatment process with the hope of further improvements from the results of treatment and a reduction in mortality.

\section{References}

1 Kamalow IL (1978) Cause of death in severe trauma of spine and spinal cord. Klin Khir 2: 74-79.

2 Kurtzke JF (1975) Epidemiology of spinal cord injury. Exper Neurol 48: 163-236.

3 Le CT, Price M (1982) Survival from spinal cord injury. J Chron Dis 35: 487-492.

4 Kraus JF, Franti ChE, Borham NO. Riggins RS (1979) Survival with an acute spinal cord injury. J Chron Dis 32: 269-283.

5 Mesars L, Carmody A, Mannarino E, Ruge D (1978) Survival after spinal cord trauma. A life table analysis. Arch Neurol 35: 78-83.

6 Sneddon DG. Bedbrook G (1982) Survival following traumatic tetraplegia. Paraplegia 20: 201-207.

7 Jäger M (1979) Spinal damages in old age and their therapy. Dutch Med J 21: 1223-1229.

8 Rossier AC, Bors E (1965) Problems of the aged with spinal cord injuries. Paraplegia 3: 34-39.

9 Kiwerski J (1992) Respiratory problems in patients with quadriplegia. Int J Rehabil Res 15: 1.

10 Kiwerski J (1989) The natural history of neurological recovery in patients with tetraplegia. Paraplegia 27: 41-45.

11 Fugl-Meyer AR, Grimby G (1971) Ventilatory function in tetraplegic patients. Scand J Rehabil Med 3: $151-160$

12 Huldtgren AC, Fugl-Meyer AR, Jonasson E, Bake B (1989) Ventilatory dysfunction and respiratory rehabilitation in post-traumatic quadriplegia. Eur J Respir Dis 61: 347-356.

13 Mackenzie CF, Shin B, Krishnaprasa D (1985) Assessment of cardiac and respiratory function during surgery of patients with acuate quadriplegia. J Neurosurg 62: 843-849.

14 Haas F, Axen K, Pinenda H (1985) Temporal pulmonary function changes in cervical cord injury. Arch Phys Med Rehabil 66: 139-144.

15 Kiwerski J (1986) Injuries of upper cervical spine. Int J Rehabil Res 9: 272-276.

16 McMichan JC, Michel L, Westbrook RR (1980) Pulmonary dysfunction following traumatic quadriplegia. JAMA 243: 528-31.

17 Simpson D (1981) Fatal injuries of the head and spine. Epidemiological studies. Med J Aust 2: 660-664.

18 Wagner KA, Kopaniky DR, Esposito L (1983) Head and spinal cord injured patients: impact of combined sequelae. Arch Phys Med Rehabil 64: 519-524.

19 Wilmot CB, Cope DN, Hall KM (1985) Occult head injury: its incidence in spinal cord injury. Arch Phys Med Rehabil 66: 227-231.

20 Charney KJ, Juler GL, Commarr AG (1975) General surgery problems in patients with spinal cord injuries. Arch Surg 110: 1083-1088.

21 Sonderstrom CA, McArdle DO, Ducker ThB (1983) The diagnosis of intra-abdominal injury in patients with cervical cord trauma. J Trauma 23: 1061-1065.

22 Kiwerski J (1986) Bleedings of alimentary duct in the course of treatment of spinal cord injury. Paraplegia 24: 92-96. 